\title{
Um xamã yanomami frente ao discurso filosófico-sociológico da modernidade
}

\author{
Leno Francisco Danner ${ }^{1}$ \\ Julie Stéfane Dorrico Peres ${ }^{2}$
}

\section{Considerações iniciais}

Este texto possui um duplo objetivo que, de todo modo, é bastante interligado. Primeiramente, pretendemos argumentar, a partir da análise da obra A queda do céu: palavras de um xamã yanomami, elaborada em parceria entre Davi Kopenawa e Bruce Albert, que a literatura indígena apresenta importante e distintiva especificidade no âmbito dos estudos literários exatamente por correlacionar de maneira imbricada e mutuamente dependente história pessoal e destino coletivo, rompendo com a noção de subjetividade absoluta que geralmente vemos no romance e na autobiografia modernos, como em Robinson Crusoé, de Daniel Defoe, em Minha vida: poesia e verdade, de Johann Wolfgang Goethe, ou, mais contemporaneamente, nas obras filosófico-literárias de Jean-Paul Sartre. Segundo, a partir do argumento de que a literatura indígena apresenta, como seu aspecto epistemológico, estético, político, antropológico e ontológico distintivo, essa correlação entre história pessoal e destino coletivo, teceremos um diálogo entre literatura e filosofia-sociologia por meio do confronto da posição de Davi Kopenawa com uma tese central das teorias da modernidade europeia canônicas na contemporaneidade mormente em Jürgen Habermas (mas também em Max Weber, por exemplo) -, a saber, de que a modernidade europeia é marcada pela imbricação entre racionalização, individuação, crítica, emancipação e universalismo, por causa da separação entre natureza, sociedade ou cultura e individualidade. Isto é, a modernidade europeia é caracterizada e definida pela separação entre história pessoal e destino coletivo, algo que as sociedades tradicionais não possuiriam nem permitiriam por serem marcadas exatamente por essa correlação entre história pessoal e destino coletivo (em nível sociocultural e ecológico-espiritual).

\footnotetext{
${ }^{1}$ Doutor em filosofia e professor da Universidade Federal de Rondônia (Unir), Porto Velho, RO, Brasil. E-mail: lenofranciscod@gmail.com

${ }^{2}$ Doutoranda em Letras na Pontifícia Universidade Católica do Rio Grande do Sul (PUC-RS), Porto Alegre, RS, Brasil. E-mail: juliedorrico@gmail.com
} 
Nesse sentido, defenderemos um duplo argumento. Em primeiro lugar - e fundamental -, que o ponto de vista crítico-emancipatório e universal é dado mais efetivamente não pelo racionalismo e a partir da racionalização como práxis, mas, sim, pelo xamanismo. Isto se dá exatamente pelo fato de que, neste, nós temos a correlação entre história pessoal e destino coletivo, que concebe a vida humana dentro de um todo espiritual-natural-cultural mais abrangente, que é condição de sua efetividade, de seu sentido e de seu futuro. Desse modo, rompe-se, em termos epistemológicos, políticos e culturais, com a ideia moderna de subjetividade fundante, separada e independente de seu contexto, com ênfase, ainda por parte da modernidade, na tecnicização da natureza, que leva diretamente à tecnicização de muitas esferas da vida humana, que perdem, em grande medida, seu substrato normativo. Nesse sentido, no xamanismo, a floresta é viva e fala a nós, e nós e ela, em simbiose, somos perpassados por uma esfera de sentido - espiritualidade-normatividade que garante e protege e dinamiza nossa evolução ao longo do tempo.

Em segundo lugar, de maneira correlata ao anterior, defenderemos que o xamanismo é a linguagem das vítimas, posto que fala universalmente: a literariedade do texto-praxis de Davi Kopenawa se remete àquela imbricação tanto para mostrar o quanto estamos unidos e dependentes em termos culturais, naturais e espirituais, de que tudo está vivo e interconectado, quanto no sentido de argumentar que, por isso, o xamanismo aponta para a necessidade de se respeitar, promover e fomentar esse substrato espiritual, cultural e ecológico se quisermos todos, indígenas e não indígenas - termos um futuro.

Desse modo, essa dupla perspectiva crítico-emancipatória permitida pela correlação entre história pessoal e destino coletivo interligadaperpassada pelo mito, possibilitada pelo xamanismo, leva à desconstrução daquela posição filosófico-sociológica das teorias da modernidade acerca da Europa e, como consequência/condição disso, acerca da cultura, da epistemologia e do homem primitivos: i) não é nada claro que a separação entre natureza, sociedade ou cultura e individualidade (a separação entre história pessoal e destino coletivo) levada a efeito pela racionalização das imagens culturais de mundo garanta individuação, crítica, emancipação e universalismo, da mesma forma como é caricato o argumento de que a correlação entre história pessoal e destino coletivo não seja racional nem gere racionalização sociocultural; ii) a crítica, a emancipação e o universalismo são gerados 
desde perspectivas epistemológicas, políticas e antropológicas plurais, e como caminhos e práticas epistemológico-políticas plurais, e não apenas a partir da racionalização moderna; e iii), nesse sentido, repetimos, o xamanismo - por meio da imbricação e mútua dependência entre história pessoal e destino coletivo mediada pelo mito - leva diretamente ao universalismo, pois enfatiza seja a voz das vítimas (ele é a voz das vítimas, em verdade), seja a atribuição de uma ligação normativoespiritual entre ontologia, ecologia e antropologia que a modernidade já não nos dá em virtude de seu tecnicismo e seu individualismo.

\section{A especificidade epistemológico-política da literatura indígena contemporânea}

Neste trabalho, consideramos que as relações que constituem a composição-estrutura-dinâmica da obra $A$ queda do céu: palavras de um xamã yanomami são pertinentes como objeto de investigação no campo dos estudos literários e filosóficos-sociológicos, pois apresentam conceitos contemporâneos que despontam em uma nova releitura, como a autoria, a coautoria, a autobiografia e a incipiente autobiografia indígena. Da mesma forma, permitem um profícuo e excitante diálogo com outras áreas das ciências humanas e sociais, como a filosofia e a sociologia para nosso caso aqui, que viabilizam o questionamento de abordagens canônicas na área exatamente sobre as culturas, povos e epistemologias tradicionais. Nosso argumento, portanto, que será melhor desenvolvido na seção seguinte, consiste em que a literatura indígena permite desconstruir interpretações caricatas das culturas, povos e epistemologias indígenas feitas por teorias filosófico-sociológicas da modernidade muito tradicionais ainda hoje no establishment acadêmico hegemônico, com sua consequente estilização bastante partidária, por assim dizer, da própria modernidade, de seu caráter especial e de sua vocação epistemológicopolítica salvacionista-cosmopolita.

Antes de entrar propriamente nessa correlação, queremos salientar a especificidade da literatura indígena contemporânea a partir da fundamental chave de leitura que é a correlação entre história pessoal e destino coletivo - em nossa percepção, aqui está o núcleo epistemológico, estético, político, antropológico e ontológico da literatura indígena, e sua grande contribuição para o enquadramento, para a crítica e para o repensar das próprias ciências humanas e sociais. Em relação a isso, 
vemos que, na contemporaneidade, a autoria dos escritores indígenas consolida-se cada vez mais e propaga-se no meio editorial brasileiro abrindo importantes campos epistemológicos e políticos para uma fecunda discussão sobre a autoria em sociedades tradicionais, validando também o conjunto de obras que compõem uma esfera literária ameríndia, caracterizada pelo movimento indígena e compreendida como exercício crítico e criativo pelos próprios indígenas. Esse fenômeno, marcado pela propagação e pelo reconhecimento das obras indígenas, também caracterizado pela afirmação da identidade indígena na escrita, evidencia a literariedade dos próprios indígenas.

O panorama histórico da edição apresentado pelas autoras Almeida e Queiroz (2004) mostra que a autoria atribuída aos povos indígenas é uma característica da contemporaneidade. Especificamente, pode-se dizer que esta prática passa a ser considerada a partir da década de 1990, mesmo que sempre tenham existido traços tipográficos e relatos indicadores de manuseio e práticas literárias entre os povos indígenas, como afirma Risério (1993). A autoria, envolvida nos aspectos autobiográficos e etnográficos, por muito tempo foi relegada, entre outras modalidades, à ideia de estabelecer a autoria àquele que possuía autoridade - no caso os pesquisadores que coletavam ou que podiam publicar as narrativas. Nessa dinâmica, os indígenas não figuravam como autores e/ou co-autores de suas próprias narrativas, nem sequer, em alguns casos, como colaboradores. Finnegan (2006) afirma que os povos de tradição oral são retratados por pesquisadores de variados interesses, que, em muitos casos, não reconhecem a autoria indígena. Conforme enfatizado pela própria autora, "negar o efeito da inspiração individual e da criatividade na literatura oral por essa razão é ignorar evidências empíricas" (Finnegan, 2006, p. 86-87), tais como as presentes na obra A queda do céu: palavras de um xamã yanomami.

A literariedade e a autobiografia indígenas, afirmadas por Sáez (2006) nos estudos mais recentes do gênero autobiográfico, perdem a característica própria do gênero autobiográfico tradicional de ser íntima e intrínseca, para ganhar contornos interativos entre o protagonista, seus editores e amanuenses, deixando isso de ser um obstáculo epistemológico para passar a primeiro plano de análise. A escrita de autobiografias indígenas equivale a uma tradução, não a uma recitação de uma lição aprendida em que os autobiógrafos acomodam dados indígenas numa estrutura recebida. A tradução é entendida pelo autor como uma tarefa 
do editor que não pretende anular dados, mas perceber que esses dados, essas obras remetem também a gêneros narrativos indígenas, que podem ser observados através de suas marcas no resultado. Nesse diapasão, as autobiografias indígenas constituem um conjunto heterogêneo, podendo ter a extensão de um relato de duas páginas, apresentar-se sob a forma de questionário ou cartas, ou constituir-se em livros completos. Elas podem ser histórias de vida projetadas ou "autobiografias cumulativas, um apanhado de documentos escritos em primeira pessoa, dos quais o analista pode inferir uma sequência autobiográfica" (Sáez, 2006, p. 180), como pode ser percebido no texto-práxis A queda do céu.

Na obra A queda do céu: palavras de um xamã yanomami, no "Postscriptum: quando eu é um outro (e vice-versa)", Bruce Albert salienta que, entre outras formas de definição para explicar a relevância da voz de Davi Kopenawa, o "eu" narrador não aparece apenas como duplicado pelo efeito autobiográfico, mas também habitado por uma multiplicidade de vozes que constituem um verdadeiro mosaico narrativo: "em primeiro lugar, para além de suas reflexões e lembranças pessoais, suas palavras se referem constantemente aos valores e à história de seu povo, e nos são transmitidas enquanto tais" (Kopenawa e Albert, 2015, p. 539). Nesse ponto, identificamos dois aspectos da autobiografia dos povos indígenas, de acordo com a conceituação dada por Sáez (2006) e por Costa (2014): ela é produzida em nome do coletivo e entrecortada pelas histórias singulares; e é extrospectiva, pois a narrativa de si não narra o eu íntimo, mas o eu mítico-histórico. Albert argumenta, enfatizando que

Nesse caso, o "eu" narrador é indissociável de um "nós" da tradição e da memória do grupo ao qual ele quer dar voz. Portanto, o que ouvimos é um "eu" coletivo tornado autoetnógrafo, movido pelo desejo ao mesmo tempo intelectual, estético, político de revelar o saber cosmológico e a história trágica dos seus aos brancos dispostos a escutá-lo (Kopenawa e Albert, 2015, p. 539).

Nesse sentido, Klinger (2006) compreende que o que vemos hoje não é um retorno da concepção da "fantasia primitivista" nos povos indígenas, mas o apagamento dela e "a reformulação da categoria do 'outro'" (Klinger, 2006, p. 78). Para ela, essa reformulação se dá por duas razões que merecem destaque: a primeira porque o excluído socialmente (o pobre, a mulher, o homossexual, o preso, o índio e o negro, por exemplo) 
começou a falar - e também a escrever - por si mesmo; e o segundo motivo porque o outro não é mais o outro radical e puro, senão que se apresenta como sujeito epistemológico, estético, político, ontológico, que é, que tem algo a dizer e que luta para dizer e afirmar-se.

Desse modo, a obra A queda do céu: palavras de um xamã yanomami é relevante para uma análise investigativa no campo das letras e das ciências humanas e sociais, pois é composta de relatos autobiográficos e reflexões xamânicas que implodem um modelo tradicional, digamos assim, de autobiografia enquanto sendo marcada (em sua forma tradicional) pela subjetividade absoluta que se diferencia diretamente, que não se reconhece diretamente frente a seu contexto (uma subjetividade que crê estar separada dele como de um objeto).

Ora, uma vez constatada a complexa relação dos conceitos, como a autobiografia indígena aqui explanada, dada a emergência da obra em uma forma que não se explicita claramente, Bruce Albert define em seus termos que a obra está escrita em primeira pessoa, a pessoa que, com vigor e inspiração, carrega a voz de Davi Kopenawa, o qual narra de modo inextricável seu eu mítico-histórico. Isto, segundo os autores Sáez (2006) e Costa (2014), seria definido como autobiografia indígena, pois as narrativas são produzidas em nome do coletivo e entrecortadas pelas histórias singulares dos indivíduos, neste caso o xamã yanomami. A narração de Davi reafirma o pressuposto aqui dado:

Quando eu era bem pequeno, meu pensamento ainda estava no esquecimento. Entretanto, costumava ver em sonho seres assustadores que chamamos yai thë. Por isso era comum me ouvirem falar e chorar durante a noite. Vivíamos então em Marakana, uma antiga casa no alto rio Toototobi. Só alguns meninos de nossa casa não sonhavam assim. Não sabíamos o que nos atrapalhava o sono, mas eram já os xapiri que vinham a nós. Por isso, mais tarde, uma vez adultos, quisemos beber o pó de yãkoana para nos tornarmos xamãs. As outras crianças cresceram sem jamais ter entendido o que nos amedrontava tanto (Kopenawa e Albert, 2015, p. 89).

Na narrativa de Davi Kopenawa, o mito está entrecortado pela vida singular do xamã Davi. A experiência creditada por ele é a tradição espiritual-cultural pela qual os jovens de sua comunidade estavam acostumados a passar. Mas o mito não é demonstrado na narrativa como algo distante ou simplesmente instrumental; ele está imbricado no 
cotidiano e na formação de Davi, bem como, de um modo mais geral, sua vida está atrelada ao seu povo.

Aqui, a autobiografia indígena é a união do singular e do plural, mas é também o reconhecimento de ambas. As pessoas, o singular "eu" e o plural "povo", não se destituem tal como geralmente as conhecemos. Nesse jogo, não podemos identificar uma dissociação do eu Davi em relação ao Davi xamã, étnico. O "eu" é também o "nós", ao passo que no "nós" está o "eu". O "eu" coletivo da pessoa narrativa traz, desse modo, um embaralhamento de pessoas na narrativa; quando isso ocorre, podemos dizer que há uma aproximação da perspectiva contemporânea da autoria em que há um desdobramento da figura do autor.

Como salienta enfaticamente Guedes (2009, p. 71) em relação às práticas autobiográficas relativas ao sujeito indígena de um modo geral e, no caso dela, à mulher indígena em particular, essas mesmas práticas autobiográficas "frequentemente adotam formas híbridas para expressar sujeitos híbridos". Nesse sentido, o estudo de autobiografias indígenas precisa levar em consideração que a tradição étnica está fundada na e basicamente imbricada à vida da comunidade indígena, de modo que a busca e a afirmação da identidade e dos valores étnicos do grupo sempre envolvem uma ação política. Por isso, "o uso do pronome 'nós', subentendido ou explícito, é uma constante, quer a narrativa seja feita na primeira pessoa do singular ou na terceira pessoa do plural" (Guedes, 2009, p. 72). Costa (2014) reforça este pressuposto ao defender que:

nessas histórias não há um "eu" absoluto, posto que sempre surge mediado, ou mesmo implicado, no "nós" narrativo. Tampouco se pode dizer que a autoria coletiva seja absoluta, pois há um reconhecimento na apresentação das obras de que se trata de uma versão da história de um povo dentre outras versões, mediada em língua portuguesa por um antropólogo. Por vezes parece que a narrativa é distante do narrador, que simplesmente relata algo passado, aparentemente desconexo à sua história de vida, mas em outras oportunidades o texto é recheado de referências biográficas, pelo fato de o mito ser constituinte do próprio narrador, que relata a sua vida por meio da história de seu clã. É essa ambivalência entre a primeira pessoa e a terceira pessoa do singular que sugere não só a ampliação de gênero autobiográfico, da qual falamos, mas também a desmontagem da ideia de um eu indivíduo individualizante (Costa, 2014, p. 96). 
Na obra A queda do céu: palavras de um xamã yanomami, vemos a profunda relação de saberes expostos do xamã com o mundo ocidental. Há uma certa preocupação em explicar ao outro, o não índio, as origens nativas e a importância dessa mesma origem para seu povo. Ao analisar a obra, em especial no que se refere a seu corpus, vemos que a autobiografia indígena, nesse sentido, como alude Sáez (2006), é a mais adequada para fins de inter-relação entre dois mundos, no caso do xamã que sai e se relaciona com o Ocidente, e este mesmo xamã que volta para sua aldeia e precisa representar, aliado ao que aprendeu em seus contatos culturais, o que ele ainda é.

O discurso autobiográfico enunciado pelas lideranças indígenas, no caso por Davi Kopenawa, está inserido no lugar em que se pode reexaminar os motivos pelos quais o xamanismo tem se estendido desde um lugar de articulação dos domínios do cosmos gerido em privado a um lugar público de representação de uma identidade indígena genérica. Em vista disso, Sáez (2006) argumenta que:

O xamã, antes um sujeito extraordinário, ou um momento extraordinário do sujeito, é agora um índio-tipo. As análises dessa representação, que se distancia de fórmulas anteriores como as do índio guerreiro ou defensor do equilíbrio natural, apontam que definir o xamanismo como uma instituição guardiã de saberes possibilita uma aliança simultânea com as ONGs internacionais e com setores nacionais interessados na defesa do patrimônio (um feito que as antigas representações estavam longe de realizar). Sem contradizer essa leitura, poderíamos acrescentar aqui que o xamanismo pode incorporar esse valor genérico porque é no xamanismo que podemos encontrar um percurso inequivocamente indígena, mas passível de formulação detalhada em termos de autobiografia: o sujeito entre mundos é um equivalente aceitável do indivíduo fora do mundo que na teoria dumontiana sugere um ponto de articulação entre as visões holistas e individualistas. Um chefe indígena poderia muito bem representar os seus seguidores, e poderia se apresentar como um guardião adequado de um conhecimento coletivo. Mas para um chefe resulta difícil compatibilizar o pressuposto de uma entidade coletivista com a criação de uma individualidade substantiva, que pelo contrário serve muito bem à legitimação pública de um xamã (Sáez, 2006, p. 194).

Quanto ao ponto da visada xamânica e etnopolítica de Davi Kopenawa, vemos o entremeio das elaborações cosmológicas e 
históricas com reminiscências pessoais, o que resulta em uma narrativa autobiográfica marcada fortemente pela correlação entre história pessoal e destino coletivo (sociocultural e ecológico-espiritual). Essa inserção autobiográfica na apresentação que se fez inicialmente oral, para daí partir para o texto escrito, entrelaça-se ao saber mítico do povo que ele apresenta ao longo da obra:

Quando me tornei homem, outros brancos resolveram me dar um nome mais uma vez. Dessa vez, era o pessoal da Funai. Começaram a me chamar de Davi "Xiriana". Mas esse nome não me agradou. "Xiriana" é como são chamados os Yanomami que vivem no rio Uricaá, muito distante de onde eu nasci. Eu não sou "Xiriana". Minha língua é diferente da dos que vivem naquele rio. [...] Meu último nome, Kopenawa, veio a mim muito mais tarde, quando me tornei mesmo um homem. Esse é um verdadeiro nome yanomami. [...] $\mathrm{Na}$ época os garimpeiros tinham começado a invadir nossa floresta. Tinham acabado de matar quatro grandes homens yanomamis, lá onde começam as terras altas, a montante do rio Hero $u$. A Funai me enviou para lá para encontrar seus corpos na mata, no meio de todos aqueles garimpeiros, que bem teriam gostado de me matar também. Não havia ninguém para me ajudar. [...] Só os espíritos xapiri estavam do meu lado naquele momento. Foram eles que quiseram me nomear. Deram-me esse nome, Kopenawa, em razão da fúria que havia em mim para enfrentar os brancos. O pai de minha esposa, o grande homem de nossa casa de Watoriki, ao pé da montanha do vento, tinha me feito beber o pó que os xamãs tiram da árvore yãkoana hi. Sob efeito do seu poder vi descer em mim os espíritos das vespas kopena. Disseram-me: "Estamos com você e iremos protegê-lo. Por isso você passará a ter esse nome: Kopenawa!" (Kopenawa e Albert, 2015, p. 71).

Sobretudo, nota-se, aludindo a Sáez (2006), a autobiografia como elo legitimador do líder com a sua comunidade. Pois ele é o mesmo mediador que relata perante os brancos sua inserção numa sociedade tradicional tanto quanto perante o seu povo. $\mathrm{O}$ discurso autobiográfico se configura como opção porque reforça o contexto em que as vozes indígenas já ganharam um espaço, de modo que a promoção da narração autobiográfica é também um modo de dotar essa voz da pluralidade que as sociedades indígenas sempre têm incluído em sua constituição enquanto nós, sem abolir o eu dessa mesma pluralidade. 
Sáez (2006) afirma ainda que as autobiografias indígenas dizem muito sobre a política indígena do multiculturalismo. E dizem também acerca dos regimes de subjetivação ameríndios, cuja relevância na hora de se apropriar dos objetos, das instituições ou dos credos ocidentais que se lhes oferecem ou impõem está sendo mostrada pela etnologia atual. São relevantes também na adaptação do próprio regime de subjetivação peculiar do Ocidente, isto é, a constituição do indivíduo e suas ocasiões por excelência, uma delas a narração autobiográfica.

Reforçamos novamente que, em A queda do céu: palavras de um xamã yanomami, os relatos dos episódios cruciais da vida de Davi Kopenawa mesclam inextricavelmente história pessoal e destino coletivo. Davi Kopenawa se expressa por intermédio de uma imbricação complexa de gêneros: mitos e narrativas de sonho, visões e profecias xamânicas, falas reportadas e exortações políticas, autoetnografia e antropologia simétrica. Esta produção une o oral e o escrito, sendo, portanto, atravessada pelos discursos de ambos os autores: um xamã yanomami e o etnógrafo conhecedor da cultura yanomami, nesse caso Bruce Albert. Percebemos que a autoria é justificada na (auto)etnografia, isto é, o outro que fala desde si mesmo e como si mesmo enquanto autoria, no sentido de que possui resistência (o outro fala, se posiciona, apresenta seus argumentos e visão de mundo) e se caracteriza pela auto-expressão, independentemente de esta ser escrita - tal como sugerem o prefácio e a composição em parceria da obra. $\mathrm{Na}$ concepção contemporânea, a "(auto)etnografia justifica quando o outro fala por si mesmo" (Klinger, 2006, p. 114). A autoetnografia também abrange desde o momento em que os "etnografados" se tornam autores de estudos sobre si mesmos até as narrativas pessoais dentro dos escritos autoetnográficos, e esse fato novamente fundamenta a singularidade da obra.

As obras indígenas e suas manifestações diversas invocam atenção ao campo do gênero literário. Tais obras, entre as quais podemos incluir $A$ queda do céu: palavras de um xamã yanomami, salientam as manifestações contemporâneas pós-modernas, ou do que podemos chamar de literaturas pós-autônomas (Ludmer, 2010), dentro do processo de valorização de um grupo marginalizado que agora toma voz para expressar-se mostrando suas particularidades, seus modos de ser antes invisíveis. A valorização de obras de cunho étnico questiona o "centro - branco, europeu, masculino, heterossexual - em todas as suas formas" (Hutcheon, 1991, p. 85). 
O conceito de decolonialidade expressa bem a valorização de obras antes (e quem sabe ainda hoje) periferizadas; mais especificamente, expressa a necessidade de atentarmo-nos teoricamente aos estudos ocorridos na própria América Latina (Mignolo, 2007). Nesse sentido, pensar em uma obra indígena é pensar primeiramente em sua própria manifestação, valorizando sua forma de expressão, como sugere a obra A queda do céu: palavras de um xamã yanomami: nela, vemos que, no campo da autoria, há um autor que faz ecoar sua ancestralidade, seu saber coletivo, étnico; há um autor que, independentemente de escrever, manifesta-se correlata e imbricadamente sobre si e sobre um grupo que ele representa. Ouvir essa voz, desse autor posto já em evidência na tipografia da capa, nos possibilita o exercício da democracia frente aos povos e grupos merecedores desta atenção.

\section{O papel e a voz do horizonte-homem primitivo na teoria da modernidade - uma crítica}

Definimos, acima, a especificidade da autobiografia indígena enquanto sendo marcada pela intersecção e mútuo sustento entre história pessoal e destino coletivo - utilizamos a obra A queda do céu: palavras de um xamã yanomami, de Davi Kopenawa e Bruce Albert, com o intuito de provar isso. Nesta seção, ainda tendo por base a referida obra, argumentaremos que tal correlação constitui-se em chave de leitura epistemológica, estética, política, antropológica e ontológica para acessarmos seja os textos narrativos indígenas (tanto orais quanto escritos), seja, de um modo mais geral, o posicionamento normativo do indígena frente a si mesmo e frente ao outro, ao não indígena neste caso, frente ao moderno, ao ocidental. A partir disso, defenderemos que a autobiografia indígena, fundada nessa correlação entre história pessoal e destino coletivo, coloca-se como instrumento teórico muito profícuo para entendermos a constituição do indígena como categoria epistemológico-política e mesmo antropológicoontológica, algo que lhe permite diferenciar-se, afirmando-se, e ao mesmo tempo contrapor-se, desafiando, ao discurso filosóficosociológico da modernidade sobre si mesma e, aqui, sua (da modernidade) visão sobre o próprio indígena. Nesse sentido, traçamos um paralelo com uma posição filosófico-sociológica fundamental entre as teorias da modernidade europeias, nesse caso, a teoria filosófico- 
sociológica da modernidade de Jürgen Habermas, uma das maiores e mais bem elaboradas do gênero na atualidade.

Em primeiro lugar, o intento de Habermas consiste em reconstruir, como já delineamos en passant, um discurso filosófico-sociológico da modernização europeia que permita delinear e fundamentar correlatamente um conceito normativo de modernidade que possibilite a crítica teórica, a reflexividade social e a emancipação política tanto dentro quanto fora da modernidade. Em segundo lugar, e como objeto desse discurso normativo, crítico, político, emancipatório, busca-se também oferecer uma perspectiva propriamente sociológica, empírica, por assim dizer, do processo de constituição e de evolução da sociedade europeia moderna e de suas instituições (Habermas, 2012a, p. 9-11). Para tanto, a estratégia metodológico-programática da teoria da modernidade de Habermas assume um duplo pressuposto: primeiro, mostrar, a partir da contraposição com as sociedades tradicionais, de base mítico-religiosa, que a modernidade europeia representa uma forma de sociedade-cultura, consciência e paradigma epistemológicopolítico superior evolutivamente falando ao tradicionalismo, o que também significa o fato de que essa mesma Europa pela primeira vez na história da evolução humana alcançou o estágio propriamente universal (porque racional), diferentemente do tradicionalismo, que permanece, por causa de sua estrutura ontológica, preso a seu contexto de emergência, incapaz de pensar-agir-fundamentar em sentido universal.

Em segundo, e como consequência dessa contraposição entre Europa como universalismo e tradicionalismo como contextualismo, a afirmação de que a cultura europeia moderna é racional e gera racionalização social, criticismo e mobilidade sociais, ao passo que o tradicionalismo, exatamente por ser preso ao seu contexto de emergência, não é racional e não gera racionalização social (Habermas, 2012a, p. 94).

Portanto, as duas estratégias metodológico-programáticas da teoria da modernidade de Habermas - sintomáticas, aliás, de todas as teorias filosófico-sociológicas da modernização europeia (por exemplo, Hegel, Marx, Weber e o próprio Habermas, conforme já citado) - consistem em: i) contrapor genericamente Europa como racionalismo-universalismo e todo o resto das sociedades como tradicionalismo-contextualismo; e ii) associar modernidade, racionalização, criticismo social, emancipação política e universalismo epistemológico-moral, recusando tal associação 
e tal possibilidade ao tradicionalismo em geral, este associado a um horizonte mágico-animista ou metafísico-teológico baseado em fundamentações essencialistas e naturalizadas - da mesma forma como se associa estas fundamentações essencialistas e naturalizadas com dogmatismo, com incapacidade de reflexividade e de crítica.

Com efeito, Habermas acredita que o caráter especial da estrutura epistemológica, política e ontológica da cultura europeia moderna fique mais claro e pungente a partir da comparação/contraposição com a visão de mundo mítica, o que provaria a racionalidade dessa mesma cultura europeia moderna em relação às visões de mundo tradicionais. Ora, as sociedades tradicionais são marcadas pela férrea imbricação entre natureza ou mundo objetivo, sociedade ou cultura e individualidade, no sentido de que a natureza aparece antropomorfizada e a sociedade, naturalizada, da mesma forma como a antropomorfização da natureza e a naturalização da sociedade subsumem as individualidades dentro dessa dinâmica mágico-animista totalizante, de modo que, em última instância, não haveria subjetividade em sentido estrito nas sociedades tradicionais. Como consequência, também não haveria criticismo e reflexividade sociais e nem emancipação política, posto que, em uma sociedade naturalizada e em uma natureza antropomorfizada, ambas de cunho mágico-animista, que enredam-subsumem os indivíduos na férrea dinâmica do eterno retorno e da eterna repetição de forças e por forças que eles não podem vencer (e não construir), somente a mágica e a religião detonadas desde autoridades e instituições centrais poderiam garantir a estabilidade, a ordem e a evolução sociais. Aqui, não apenas não haveria necessidade de crítica social e de práxis política, senão que elas seriam exatamente impedidas de vir à tona, de se desenvolverem por causa tanto dessa férrea imbricação acima comentada quanto do caráter mágicoanimista da sociedade e da natureza (Habermas, 2012a, p. 94-119).

Ora, qual a característica fundamental da cultura europeia moderna que a diferencia das sociedades tradicionais como um todo e, ao mesmo tempo, lhe confere um sentido universal, diferentemente das sociedades tradicionais? Para Habermas é exatamente a separação entre natureza ou mundo objetivo, sociedade ou cultura e individualidade, causada e desenvolvida por um processo gradativo, longo e árduo de racionalização social-cultural-institucional - nesse sentido, a sociedade europeia moderna seria o antípoda das sociedades mítico-tradicionais. A separação entre natureza ou mundo objetivo, sociedade ou cultura e individualidade 
implica na historicidade e na politização da sociedade-cultura, em sua completa secularização e profanização, assim como na completa tecnicalidade da natureza, esta transformada em pura res extensa, para utilizar um termo de René Descartes, sem qualquer sentido normativo, religioso, ontológico, moral. Por outras palavras, aquela separação, acontecida na sociedade europeia moderna, gestada, desenvolvida e fomentada por ela, leva à queda das fundamentações essencialistas e naturalizadas, metafísico-teológicas e mágico-animistas no que diz respeito à compreensão, fundamentação e ação humanas frente à natureza, à sociedade e à individualidade. A sociedade-cultura é uma construção humana, e a natureza é mero objeto material, físico-químico: doravante, cabe ao próprio homem dar sentido a elas, construí-las enquanto um todo dotado de sentido, geri-las etc. (Habermas, 2012a, p. 139).

A separação entre natureza, cultura e individualidade consolida a racionalização como a base paradigmática para a constituição da sociedade e da cultura, bem como para a autocompreensão do próprio indivíduo moderno em relação a si mesmo, à sociedade e ao mundo natural de um modo mais geral. Ela gera criticismo e mobilidade sociais e emancipação política, no entender de Habermas, exatamente por politizar e por historicizar as instituições sociais, os sujeitos epistemológicopolíticos e as práticas morais constitutivas da sociedade e da cultura.

A racionalização desnaturaliza e, portanto, politiza a sociedadecultura e os sujeitos epistemológico-políticos, contrariamente às visões mágico-animistas, que naturalizam e, assim, despolitizam tanto a sociedade-cultura quanto os sujeitos epistemológico-políticos. Note-se, aqui, além disso, o aspecto fundamental da sociedade europeia moderna, garantidor de seu enquadramento, transformação e evolução ao longo do tempo, a saber, o indivíduo. Este é totalmente independente da sociedade-cultura em que vive e emerge, não no sentido de que ele não possui uma ontogênese social e uma localização espaço-temporalcultural em dado contexto, senão que, mesmo diante desse fato óbvio, esse mesmo indivíduo europeu moderno percebe-se como independente do meio sociocultural e natural, no sentido de que eles são um meio à mão, à posse epistemológico-política do indivíduo fundante. O mundo, no dizer de Kant, é uma construção do sujeito que significa e, se há existência (com sentido), ela depende do fato de que a razão humana é normativa, dá sentido, constrói sentido - não há nada prévio, tudo depende da ação do homem. Com isso, o indivíduo é 
independente e sobreposto ao mundo sociocultural e natural, objetificando-o, politizando-o, criando-o, em verdade.

Para Habermas, assim como para a filosofia moderna como um todo, esta é a condição fundamental para a reflexividade e mobilidade sociais e para a ação política: a autonomia e sobreposição do indivíduo em relação ao contexto sociocultural e natural de que emerge. Não mais a correlação entre história pessoal e destino coletivo, entre constituição individual e dinâmica mágico-animista e sociocultural e ecológica, mas estas mesmas independência e sobreposição do indivíduo em relação ao contexto se tornam a consequência e a condição da racionalidade, da racionalização sociopolítica.

Nesse sentido, aparece também o outro aspecto fundamental para esta associação entre modernidade, crítica e emancipação, que é a racionalização cultural. Esta implica em que a sociedade moderna e seus indivíduos e seus grupos saibam diferenciar o que são natureza, cultura e individualidade, primeiro no sentido de entendê-los em um sentido técnico (no caso da natureza) e político-normativo (no caso da cultura e do indivíduo) e, segundo, como consequência, no sentido de saber diferenciar juízos descritivos, normativos, avaliativos, explicativos e expressivos, a partir de procedimentos e formas de fundamentação específicos a cada caso. Aqui, a explicitação-fundamentação das condições lógico-argumentativas próprias a cada caso especifica e potencializa a racionalização social, epistemológica e política que é a característica fundamental da sociedade moderna, que a torna universal porque racional (Habermas, 2012a, p. 140-141; Habermas, 2012b, p. 196-202).

Mas o que é racionalização social? É a capacidade de pensar-agirfundamentar sem referência direta ao contexto material-simbólico de que se emerge, o que também significa a capacidade de fundamentar normas e práticas a partir da abstração relativamente às fundamentações essencialistas e naturalizadas, mágico-animistas e metafísico-teológicas (que, de todo modo, são entendidas pelo indivíduo moderno como uma sua construção). Da mesma forma, ao abrir mão dessas fundamentações essencialistas e naturalizadas, mágico-animistas e metafísico-teológicas, a cultura e o indivíduo modernos aprendem a diferenciar os conteúdos simbólicos específicos a cada área - para nosso exemplo aqui, o que é próprio do horizonte (técnico) natural, o que é próprio do horizonte (político-normativo) 
cultural-societal, o que é próprio da postura (estético-expressiva) individual e, finalmente, o que é próprio exatamente de cada visão de mundo (religião, metafísica). Para o homem moderno, portanto, marcado indelevelmente pela prensa da racionalização, nem tudo obedece a critérios mágico-animistas ou metafísico-teológicos, senão que há uma diferenciação muito clara entre as esferas de valor acima citadas (Habermas, 2012a, p. 86, p. 95).

Como consequência da separação entre natureza ou mundo objetivo, cultura ou sociedade e individualidade, bem como da diferenciação e da especificação muito estritas da singularidade de cada esfera de valor com sua dinâmica própria de fundamentação (o político funciona de um jeito, o técnico de outro, o teológico de outro, o estético de outro etc.), a cultura e os indivíduos modernos são marcados, no que tange à fundamentação dos valores e das práticas, por uma consciência epistemológico-moral descentrada, isto é, por uma postura pósconvencional caracterizada pela atitude e pela perspectiva não etnocêntricas e não egocêntricas, em que o indivíduo maduro possui a capacidade de colocar-se no lugar dos outros exatamente por causa daquela diferenciação entre natureza, cultura e individualidade enquanto marca da modernização. Por isso mesmo, a fundamentação dos valores e das práticas, assim como a práxis político-normativa, desses mesmos indivíduos modernos são caracterizadas como um procedimentalismo imparcial, neutro, formal e impessoal relativamente aos contextos prático-materiais, no sentido de que aqueles podem pensar-agir-fundamentar sem referência direta a estes.

Na teoria da modernidade de Jürgen Habermas, essa condição da modernidade cultural europeia adveniente de sua separação entre natureza ou mundo objetivo, cultura ou sociedade e individualidade, que é a consequência da racionalização cultural das imagens metafísico-teológicas e mágico-animistas de mundo, permite um duplo aspecto próprio a essa mesma modernidade cultural: primeiro, qualquer valor e prática legitimados intersubjetivamente precisam despir-se, fundamentalmente, de sua referência direta ao contexto material-cultural-epistemológico de que emergem, isto é, eles não podem estar baseados em fundamentações essencialistas e naturalizadas; segundo, somente a racionalização da fundamentação dos valores e da práxis ético-política, que, por causa disso, perde sua base metafísico-teológica, mágico-animista, permite a 
consolidação de uma perspectiva epistemológico-política universal, crítica e emancipatória (Habermas, 1990, 2012a; 2012b; Forst, 2010).

Nesse sentido, a contraposição da modernidade em relação ao tradicionalismo, pelas teorias da modernidade europeias de um modo geral (Hegel, Comte, Marx, Weber etc.) e pela teoria da modernidade de Habermas em particular, permite concluir que, por não existir racionalização nas sociedades-culturas tradicionais, também não existe nelas e por elas individuação, crítica, emancipação e universalidade. Diz Habermas:

Imagens de mundo míticas não são entendidas pelos envolvidos como sistemas interpretativos atrelados a uma tradição cultural, constituídos por nexos internos de sentido, simbolicamente referidos à realidade, vinculados a pretensões de validade e, por isso, passíveis de crítica e aptos à revisão (Habermas, 2012a, p. 109).

Isto é, imagens de mundo míticas são percebidas como sobrehumanas; elas não são criações humanas, próprias a mundos socioculturais de cunho histórico, em certo sentido fabricado. Por isso, enquanto sobre-humanas, enquanto essencialistas e naturalizadas, elas escapam a qualquer possibilidade de racionalização, a qualquer possibilidade de enquadramento lógico-técnico ou político-normativo. Em síntese, elas não são construções humanas em absoluto e, por serem essencialistas e naturalizadas, subsumem os indivíduos e os grupos sociais a esses fundamentos dogmáticos, acríticos, totalizantes e apagadores de qualquer noção de individualidade, assim como deslegitimadores de qualquer práxis transformadora. Com isso, não haveria crítica, mobilidade, emancipação e universalismo - posto que não haveria racionalização cultural - nas sociedades tradicionais. Essa, como vimos dizendo, é a imagem que as teorias da modernidade europeias, em termos sociológico-filosóficos, fazem de si mesmas a partir da contraposição com as sociedades/culturas/epistemologias tradicionais.

A Europa moderna é, como um todo imbricado, marcada pela racionalização, pela historicidade, pela noção de subjetividade reflexiva e, com isso, ela é crítica, emancipatória e universal; em contrapartida, as sociedades mítico-tradicionais como um todo não são racionais e, por isso, são presas a seu contexto (mágico-animista, metafísico-teológico) vital, incapazes de politização, de historicização, de individuação, de crítica, de emancipação e de universalização, tanto por não entenderem-se a si mesmas como produto humano, como evento histórico-político, quanto por não apresentarem uma noção de indivíduo reflexivo enquanto sujeito 
epistemológico-político que se diferencia e se independentiza do ambiente natural-cultural de que emerge - logo, sociedades mítico-tradicionais e seus indivíduos e grupos socioculturais são dogmáticos, incapazes de universalização, isto é, de assumirem uma postura não egocêntrica e não etnocêntrica referentemente a valores e a práticas (Weber, 1984, p. 11-24; Habermas, 2002, p. 3; Habermas, 2012a, p. 94-141).

Com isso, aparecem duas características fundamentais das teorias da modernidade europeias que gostaríamos de utilizar com o objetivo de discutir, a partir da análise da obra $A$ queda do céu: palavras de um xamã Yanomami, de Davi Kopenawa e Bruce Albert, e sob uma perspectiva interdisciplinar, o sentido prático, normativo da reflexão filosóficoliterária. Essas duas características são: i) o fato de que, nas teorias da modernidade, somente uma posição universalista ao estilo da modernidade cultural europeia e como racionalização pode falar não apenas em seu nome, mas em nome de todos os contextos, culturas, epistemologias e grupos socioculturais - ou, pelo menos, o fato de que somente assumindo-se esse conteúdo epistemológico-político-normativo da modernidade cultural europeia poder-se-ia falar-agir-fundamentar em nome de todos e para todos; e ii) o fato de que somente a separação entre história pessoal e destino coletivo (destino coletivo seja enquanto subsunção ao horizonte sociocultural, seja como subsunção ao entorno natural-espiritual e cósmico-ontológico, e desde uma perspectiva mágicoanimista), com a consolidação de uma noção de subjetividade reflexiva que é independente e, em grande medida, contraposta à natureza e à cultura/sociedade, permite, gera e fomenta a racionalização dos valores e das práticas, a tecnicização da natureza e a politização e historicização da sociedade-cultura, de suas instituições, de suas práticas, de seus valores e de seus sujeitos epistemológico-políticos.

Nesse sentido, a correlação entre história pessoal e destino coletivo, nos termos que a primeira parte do texto nos apresenta, nos termos em que Davi Kopenawa nos apresenta em sua magnífica obra-práxis, ao ligar indelevelmente história pessoal e destino coletivo a partir de uma perspectiva mágico-animista, metafísico-teológica (para usar termos das teorias da modernidade europeias), não permite a correlação entre racionalização, historicização, politização, individuação, crítica, emancipação e, finalmente, universalismo. Com isso, se seguíssemos as teorias da modernidade tradicionais (e, para o que nos interessa aqui, a teoria da modernidade de Habermas em particular), Davi Kopenawa 
não poderia apresentar uma perspectiva crítico-emancipatória que é universal e que é reflexiva. Esse, pelo menos, é um argumento que pode ser inferido sem nenhum problema das teorias da modernidade de Weber e de Habermas: a correlação de história pessoal e destino coletivo mediada pelo mito não é racional e nem gera racionalização (ao estilo da modernidade europeia), o que significa que ela não é nem crítica, nem emancipatória e nem universal.

Neste texto e no texto de Davi Kopenawa e Bruce Albert, essa visão idílica da modernidade cultural europeia e, por outro lado, mas como consequência/condição para se sustentar tal visão idílica de modernidade cultural europeia (modernidade, racionalização, individuação, crítica, emancipação e universalismo), a visão diminuída do horizonte mítico-tradicional (fundamentos essencialistas e naturalizados, prisão do/ao contexto, dogmatismo), são negadas por nós. Antes de justificarmos isso, acreditamos haver uma conexão profunda e verdadeiramente empolgante entre literatura, filosofia e vida: quando saímos um pouco do academicismo exagerado (a teoria pela teoria), percebemos nas ciências humanas e sociais e na literatura uma conexão impressionante e alentadora com a vida corrente, com o dia a dia cotidiano, com as pessoas de carne e osso, por assim dizer. Por que dizemos isso? Porque uma das tônicas deste nosso texto consiste em apontar exatamente para a vinculação do texto com os valores, práticas e símbolos, do texto como valor, prática e símbolo para a e da vida cotidiana; da mesma forma, um dos aspectos absolutamente incríveis da literatura e da filosofia e da sociologia (mas também da pedagogia, da história etc.), que estamos assumindo aqui, consiste no fato de que o sujeito da teoria também é o sujeito da política, também é o sujeito da práxis, e isto significa: ele parte de um mundo normativo e quer refletir-agir sobre ele. Como sujeito da teoria, ele fala política e normativamente; como sujeito da práxis, ele fala teoricamente. São aspectos que não podem e nem devem ser dissociados. São aspectos que, pelo menos no âmbito das ciências humanas e sociais e, aqui, da literatura, não permitem uma tecnicização conforme certo estilo tradicional de pesquisa e de entendimento do sujeito epistemológico em ciências naturais, para o qual um procedimentalismo dinamizado enquanto neutralidade, formalização, impessoalidade e abstração representam os eixos estruturantes da objetividade epistemológico-normativa. 
É exatamente por tal conexão entre texto e práxis, texto como práxis, e sujeito epistêmico e sujeito político, o sujeito epistêmico como sujeito político, que podemos não apenas acessar o texto de Davi Kopenawa e Bruce Albert, mas também, e mais importante para o propósito deste artigo, desconstruir a visão tradicional das teorias da modernidade sobre si mesmas e, como consequência, sobre a cultura e o indivíduo primitivos. Novamente, essa visão da modernidade sobre si mesma e sobre o primitivo, que concebe a racionalidade-racionalização como categoria fundante e definidora da modernidade europeia (quando se fala em modernidade, é da modernidade europeia de que se está falando), como categoria fundante que a separa de uma vez por todas em relação a todo o resto como tradicionalismo, essa visão, como dizíamos, possui um duplo pressuposto, que é: i) a associação entre modernidade-modernização, racionalização, individuação, crítica, emancipação e universalismo; e ii) a separação entre história pessoal e destino coletivo, no sentido de que tal separação permite tanto a secularização, profanização, historicização e politização da sociedade-cultura e da natureza-religião quanto a consolidação de uma noção de indivíduo reflexivo e fundante que, separado e independente da sociedade/cultura e da natureza/religião, coloca-se como a base delas, seu dinamizador, como sua construção, política no primeiro caso, técnica no segundo.

É nesse sentido que o texto-práxis A queda do céu: palavras de um xamã yanomami traz à cena epistemológico-política e como epistemologia-política a afirmação de que é exatamente o xamanismo - a íntima imbricação entre natureza, cultura-sociedade e individualidade, mediada pela magia, subsumida por esta - que permite tanto a correlação entre crítica, emancipação e universalismo quanto um discurso sobre a modernização que, já não mais apelando ao tipo de racionalização próprio do cientificismo moderno - lógico-formal, como procedimentalismo imparcial, neutro, formal e impessoal quanto à fundamentação dos valores e das práticas -, permite recuperar um ideal de ecologia integral e de sociabilidade não patológica mutuamente dependentes e em correlação absolutamente estrita, que encontra no horizonte metafísico-teológico ou mágico-animista os pilares e as motivações para a não tecnicização seja da natureza, seja do próprio ser humano - uma tecnicização, diga-se de passagem, que é sempre totalizante, isto é, se afeta a natureza, afeta diretamente o ser humano, e vice-versa. 
Assim, o xamanismo explicita a voz da floresta, de seus animais e dos deuses que a sustentam, por meio da voz do xamã que, ao escutálas efetivamente, quer transmitir ao homem moderno, que somente escuta a si mesmo por meio da técnica, o perigo da tecnicização e da instrumentalização, assim como a dor sofrida pela floresta viva. Uma passagem muito importante de A queda do céu: palavras de um xamã yanomami pode nos dar uma ideia do que estamos falando aqui. Entregando seu testemunho sob a forma desse livro a Bruce Albert, Davi Kopenawa insta a que ele o transmita aos brancos para que eles possam repensar a postura da modernização sobre si mesma em seu movimento tecnicizante imparável e totalizante e, como consequência, também a atitude tecnicista-colonizadora dessa mesma modernização em relação à natureza e às culturas tradicionais, a partir da escuta da voz da floresta, de seus seres e dos povos que a habitam. Senão vejamos esta linda fala-práxis xamânica:

Como eu, você ficou mais experiente com a idade. Você desenhou e fixou essas palavras em peles de papel, como pedi. Elas partiram, afastaram-se de mim. Agora desejo que elas se dividam e se espalhem bem longe, para serem realmente ouvidas. Eu lhe ensinei essas coisas para que você as transmita aos seus; aos seus mais anciãos, aos seus pais e sogros, aos seus irmãos e cunhados, às mulheres que você chama de esposas, aos rapazes que irão chamá-lo de sogro. Se lhe perguntarem: "Como você aprendeu essas coisas?", você responderá: "Morei muito tempo nas casas dos Yanomami, comendo sua comida. Foi assim que, aos poucos, sua língua pegou em mim. Então, eles me confiaram suas palavras, porque lhes dói o fato de os brancos serem tão ignorantes a seu respeito".

Os brancos não pensam muito adiante no futuro. Sempre estão preocupados demais com as coisas do momento. É por isso que eu gostaria que eles ouvissem minhas palavras através dos desenhos que você fez delas; para que penetrem em suas mentes. Gostaria que, após tê-las compreendido, dissessem a si mesmos: “Os Yanomami são gente diferente de nós e, no entanto, suas palavras são retas e claras. Agora entendemos o que eles pensam. São palavras verdadeiras! A floresta deles é bela e silenciosa. Eles ali foram criados e vivem sem preocupação desde o primeiro tempo. O pensamento deles segue caminhos outros que o da mercadoria. Eles querem viver como lhes apraz. Seu costume é 
diferente. Não têm peles de imagens, mas conhecem os espíritos xapiri e seus cantos. Querem defender sua terra porque desejam continuar vivendo nela como antigamente. Assim seja! Se eles não a protegerem, seus filhos não terão lugar para viver felizes. Vão pensar que a seus pais de fato faltava inteligência, já que só terão deixado para eles uma terra nua e queimada, impregnada de fumaças de epidemia e cortada por rios de águas sujas!".

Gostaria que os brancos parassem de pensar que a nossa floresta é morta e que ela foi posta lá à toa. Quero fazê-los escutar a voz dos xapiri, que ali brincam sem parar, dançando sobre seus espelhos resplandecentes. Quem sabe assim eles queiram defendê-la conosco? Quero também que os filhos e filhas deles entendam nossas palavras e fiquem amigos dos nossos, para que não cresçam na ignorância. Porque, se a floresta for completamente devastada, nunca mais vai nascer outra. Descendo desses habitantes da terra das nascentes dos rios, filhos e genros de Omama. São as palavras dele, e as dos xapiri, surgidas no tempo do sonho, que desejo oferecer aqui aos brancos. Nossos antepassados as possuíam desde o primeiro tempo. Depois, quando chegou a minha vez de me tornar xamã, a imagem de Omama as colocou em meu peito. Desde então, meu pensamento vai de uma para outra, em todas as direções; elas aumentam em mim sem fim. Assim é. Meu único professor foi Omama. São as palavras dele, vindas dos meus maiores, que me tornaram mais inteligente. Minhas palavras não têm outra origem. As dos brancos são bem diferentes. Eles são engenhosos, é verdade, mas carecem muito de sabedoria (Kopenawa e Albert, 2015, p. 64-65).

Como se pode perceber pela passagem acima, o xamanismo explicita a voz das vítimas, a racionalização não, pelo menos não com tanta intensidade, pungência e sensibilidade. E por que o xamanismo explicita a voz das vítimas de modo mais efetivo que a racionalização? Exatamente pelo fato de entendê-las sempre desde um ponto de vista mágico-animista totalmente normativo-político que a lógica técnico-científica da modernização destruiu: a natureza é viva, fala, sente amor e dor, abençoa ou amaldiçoa e, sobretudo, ela é a condição absolutamente fundante para a vida (e não a individualidade moderna). E, para ganhar dela bênçãos e benesses, não apenas o ritual, mas principalmente o cuidado e a sensibilidade, que a protegem, a valorizam e a promovem, adquirem papel central. Da mesma forma, o xamanismo representa e é a voz das 
vítimas na medida em que ele apela à sensibilidade e ao cuidado para tudo aquilo que não pode ser enquadrado pura e simplesmente em uma categoria técnica e/ou econômica: cada ser, desde uma árvore a um animal e chegando ao homem, possui uma profunda estrutura normativo-espiritual, uma fundamental ligação e dependência a um todo societal-cultural e ecológico-espiritual, cósmico-metafísico, que não apenas é maior que ele, senão que é também sua condição de possibilidade. Por isso, por causa dessa ligação e dessa dependência, deve haver uma harmonia permanente, um cuidado, respeito e promoção permanentes de todas estas esferas.

Com isso, argumentamos que o xamanismo fala universalmente, mas a racionalização incide sobre um tipo específico de particularidade, a saber, a técnica e desde uma perspectiva técnica e individualizante. Ora, por que o xamanismo fala universalmente? Pelo fato de que falar universalmente significa estar comprometido com e ligado a algo/alguém, ter sensibilidade para escutar uma voz que, infelizmente, apenas os xamãs - e Davi Kopenawa é um xamã - ainda escutam, por não estarem totalmente subsumidos na racionalização, no tecnicismo e na individualização exacerbada. O xamanismo fala universalmente porque não dissocia a ligação efetiva que existe entre natureza e culturasociedade e individualidade desde um prisma normativo-espiritual-natural. É por causa dessa ligação que podemos sentir-nos parte de algo maior e que é nossa condição, é por causa dela que podemos e devemos nos preocupar com os outros e eles conosco.

Desse modo, o xamanismo fala universalmente por enfatizar a correlação entre história pessoal e destino coletivo (societal-cultural e ecológico-espiritual), por explicitar um fato óbvio da vida de todos nós, que teimamos em achar secundário ou periférico em relação ao desenvolvimento, à racionalização ou ao nosso próprio ego: de que somos todos um, de que surgimos, dependemos e voltaremos sempre para uma unidade fundamental com todos os seres como naturezaespiritualidade, cultura-sociedade, amor-reciprocidade que jamais será apagada e que, quanto mais ignorada, mais cobra a conta sob a forma de desilusão, violência e crise. $\mathrm{O}$ xamanismo concebe o todo e cada coisa-ser em particular como políticos, como normativos, daí nossa afirmação de que ele é a voz das vítimas, das diferenças, falando universalmente. Nesse sentido, a passagem acima, de Davi Kopenawa, nos mostra que, contrariamente à caricatura feita dos povos, culturas e 
epistemologias tradicionais enquanto não racionais, dogmáticos, não críticos, não emancipatórios e não universais, é exatamente a falapráxis xamânica que ainda guarda a sensibilidade para com o outro, a preocupação para com ele, a ligação ontológica, epistemológica, normativa e política que temos uns com os outros desde sempre, de uma vez por todas - é ela, portanto, muito mais do que a racionalização, que ainda possibilita o discurso-práxis universal, o discurso-práxis das vítimas, das diferenças.

\section{Referências}

ALMEIDA, Maria Inês; QUEIROZ, Sônia (Org.) (2004). Na captura da voz: as edições da narrativa oral no Brasil. Belo Horizonte: Autêntica.

COSTA, Suzane Lima (2014). Povos indígenas e suas narrativas autobiográficas. Estudos Linguísticos e Literários, Salvador, n. 50, p. 65-82, jul./dez.

FINNEGAN, Rute (2006). O significado da literatura em culturas orais. In: QUEIROZ, Sônia (Org.) A tradição oral. Belo Horizonte: Fale/UFMG. p. 64-102.

FORST, Rainer (2010). Contextos da justiça: filosofia política para além de liberalismo e comunitarismo. São Paulo: Boitempo.

GUEDES, Peonia Viana (2009). Narrando o sujeito feminino de origem indígena: práticas autobiográficas na construção de identidades pessoais e culturais. In: HARRIS, Leila Assumpção (Org.). A voz e o olhar do outro. Rio de Janeiro: Letra Capital. p. 68-80.

HABERMAS, Jürgen (1990). Pensamento pós-metafísico. Rio de Janeiro: Tempo Brasileiro.

HABERMAS, Jürgen (2002). O discurso filosófico da modernidade: doze lições. São Paulo: Martins Fontes.

HABERMAS, Jürgen (2012a). Teoria do agir comunicativo: racionalidade da ação e racionalização social São Paulo: Martins Fontes. v. I.

HABERMAS, Jürgen (2012b). Teoria do agir comunicativo: sobre a crítica da razão funcionalista São Paulo: Martins Fontes. v. II.

HUTCHEON, Linda (1991). Poética do pós-modernismo: história, teoria, ficção. Rio de Janeiro: Imago. 
KLINGER, Diana Irene (2006). Escritas de si, escritas do outro: autoficção e etnografia na narrativa latino-americana contemporânea. Tese (Doutorado em Literatura) - Universidade do Estado do Rio de Janeiro, Rio de Janeiro.

KOPENAWA, Davi; ALBERT, Bruce (2015). A queda do céu: palavras de um xamã yanomami. São Paulo: Companhia das Letras.

LUDMER, Josefine (2007). Literaturas pós-autônomas. Ciberletras: Revista de Crítica Literaria y de Cultura, Bronx, n. 17, p. 1-6.

MIGNOLO, Walter D. (2007). La idea de América Latina: la herida colonial y la opción decolonial. Barcelona: Gedisa.

RISÉRIO, Antonio (1993). Textos e Tribos: poéticas extraocidentais nos trópicos brasileiros. Rio de Janeiro: Imago.

SÁEZ, Oscar Calavia (2006). Autobiografia e sujeito histórico indígena. Novos Estudos (CEBRAP), São Paulo, n. 76, p. 179-195.

WEBER, Max (1987). Sociología de la religión. Madrid: Taurus. v. I.

Recebido em 26 de fevereiro de 2017.

Aprovado em 17 de julho de 2017.

\section{resumo/abstract/resumen}

\section{Um xamã yanomami frente ao discurso filosófico-sociológico da modernidade}

Leno Francisco Danner e Julie Stéfane Dorrico Peres

Neste texto, que procura tecer um diálogo entre literatura e filosofia-sociologia, desenvolvemos um duplo argumento, tendo por base uma discussão entre a obra A queda do céu: palavras de um xamã yanomami, de Davi Kopenawa e Bruce Albert, e a teoria filosófico-sociológica da modernidade de Jürgen Habermas: i) a marca distintiva da literatura indígena, em seu gênero autobiográfico, consiste na fundamental correlação entre história pessoal e destino coletivo (em nível sociocultural e ecológico-espiritual), dinamizada pelo e baseada no mito, de modo que tal correlação entre identidade pessoal e destino coletivo oferece-se como chave de leitura epistemológica, estética, política, antropológica e ontológica para acessarmos o texto-praxis indígena; ii) ela nos permite desconstruir uma visão idílica da Europa moderna sobre si mesma e seu entendimento caricato das culturas, das epistemologias e dos homens primitivos (não modernos, pré-modernos - porque depois da modernidade não se teria 
mais nada, já que ela é o ápice evolutivo, epistemológico, ontológico da humanidade), em que, primeiro, a modernidade seria racional, gerando individuação, criticismo, emancipação e universalismo, por causa da separação entre história pessoal e destino coletivo, bem como, segundo, a cultura tradicional não geraria racionalização, nem criticismo, nem emancipação e nem universalismo, por estar marcada pela férrea imbricação entre história pessoal e destino coletivo mediada pelo mito. Com isso, argumentamos que o xamanismo, muito mais que a modernização, pode ser entendido efetivamente como a voz das vítimas, como a voz das diferenças, possibilitando a perspectiva crítico-emancipatória universal, exatamente por tornar vivos, interligados e normativos todos os aspectos de nossa existência a partir da correlação entre história pessoal e destino coletivo mediada pelo mito.

Palavras-chave: literatura indígena, xamanismo, modernidade, razão.

\section{A Yanomami Shaman against the philosophical-sociological discourse of modernity}

\section{Leno Francisco Danner e Julie Stéfane Dorrico Peres}

In this paper, which intends to establish a dialogue between literature and philosophy-sociology, we develop a double argument. Based on the discussion of Davi Kopenawa's and Bruce Albert's The falling sky: words of a Yanomami Shaman and Jürgen Habermas' philosophical-sociological theory of modernity the essay discusses: $i$ ) the distinctive characteristic of Indigenous literature. We maintain that this distinction lies in the conjunction between its self-biographical style, and the fundamental correlation between personal history and collective destiny (at the social-cultural and ecological-spiritual levels), invigorated by and based on myth, so that such a correlation between personal history and collective destiny becomes the epistemological, political anthropological and ontological key to access the Indigenous text-praxis; ii) it allows us to deconstruct an idyllic vision of Europe about itself and its caricature of primitive cultures, epistemologies and peoples (as non-modern, pre-modern - because after modernity there is nothing else, as it is the evolutionary, epistemological and ontological apogee of humankind), in which, firstly, modernity is rational and generates individualization, critical thinking, emancipation and universalism, because of the separation between personal history and collective destiny, while, secondly, traditional culture does not generate rationalization, or critical thinking, or emancipation or universalism, since it is marked by the strong imbrication between personal history and collective destiny and is permeated by myth. With that, we argue that shamanism, more than modernization, can be effectively understood as the victim's voice, as the other's voice, allowing for a universal critical-emancipatory perspective that allows for an 
interconnected existence based on the correlation between personal history and collective destiny mediated by myth.

Keywords: indigenous literature, shamanism, modernity, reason.

\section{Un chamán yanomami frente al discurso filosófico-sociológico de la modernidad}

\section{Leno Francisco Danner e Julie Stéfane Dorrico Peres}

En este texto, que busca tejer un diálogo entre la literatura y la filosofíasociología, desarrollaremos un doble argumento, basado en una discusión entre la obra La caída del cielo: palabras de un chamán yanomami, de David Kopenawa y Bruce Albert, y la teoría filosófico-sociológica de la modernidad de Jürgen Habermas: i) el sello distintivo de la literatura indígena, en su género autobiográfico, consiste en la correlación fundamental entre historia personal y destino colectivo (en el nivel socio-cultural y ecológico-espiritual), dinamizada por y basada en el mito, de manera que tal correlación entre la identidad personal y el destino colectivo se ofrece como una clave de lectura epistemológica, estética, política, antropológica y ontológica para acceder al texto-praxis indígena; ii) ello permite deconstruir la visión idílica que la Europa moderna tiene sobre sí misma y su comprensión caricaturesca de las culturas, las epistemologías y los hombres primitivos (no modernos, pre-modernos porque después de la modernidad no se tendría más nada, ya ella es el vértice de la evolución humana, en términos epistemológicos y ontológicos), en la que, en primer lugar, la modernidad sería racional, generando la individulización, la crítica, la emancipación y el universalismo, debido a la separación entre historia personal y destino colectivo, y en segundo lugar, la cultura tradicional no generaría racionalización ni crítica, ni emancipación ni universalismo, al ser marcada por la imbricación entre la historia personal y el destino colectivo mediado por el mito. Por lo tanto, sostenemos que el chamanismo, mucho más que la modernización, puede ser entendido de manera efectiva como la voz de las víctimas, como la voz de las diferencias, posibilitando la perspectiva crítica y emancipadora universal, exactamente por tornar vivos, interligados y normativos todos los aspectos de nuestra existencia a partir de la correlación entre la historia personal y destino colectivo mediada por el mito.

Palabras-clave: literatura india, chamanismo, modernidad, razón. 